\title{
The sound environment and soundscape preservation in historic city centres - the case study of Lhasa
}

\author{
Lingjiang Huang ${ }^{\mathrm{a}}$ Jian Kang ${ }^{\mathrm{b}^{*}}$ \\ ${ }^{a}$ Department of Architecture, Wuhan University, Wuhan, Hubei, People's Republic of \\ China \\ ${ }^{\mathrm{b}}$ School of Architecture, University of Sheffield, Western Bank, Sheffield S10 2TN, \\ United Kingdom \\ *Corresponding Author
}

\begin{abstract}
The historic city centre of Lhasa has preserved special types of historic and cultural heritage for various reasons, including strong religious beliefs, preservation policy, and slow globalisation. In addition to visual cultural heritage, the sound environment represents a cultural heritage that requires preservation. This paper presents an analysis of the sound environment of Lhasa's historic city centre based on field investigations and soundwalk measurements during the tourism high season. First, Lhasa's historic urban form and cultural background are introduced. Second, the relationship between the historic urban space and the sounds is investigated according to the sound sources. The sound taxonomy and the cultural meanings of these sounds are examined and identified. Third, the sound environments are evaluated from the perspectives of sound sources and sound changes with time and frequency. The sound pressure level is determined to be high in the historic centre, which might affect the sound sources associated with cultural identities. Additionally, significant variations within the centre-both spatial and temporal - that are identified in the sound pressure levels and spectrums are reflected the characteristics of local daily life and social activities. Finally, comparisons are made between Lhasa's historic centre and a number of other historic centres and squares. Possible implications of the results and principles of soundscape preservation are also discussed based on the case study of Lhasa.
\end{abstract}


Lingjiang Huang \& Jian Kang: Sound Environment and Soundscape Preservation doi:10.1068/b130073p

Keywords: sound environment, historic city centre, sound, soundscape preservation, Lhasa

2015 Environment and Planning B: Planning and Design

Received: 7 May 2013; in revised form: 28 October 2013

Published Online: 18 February 2015

\section{Introduction}

The historic urban environment is characterised by a variety of social and cultural activities, as well as tourism and has generally been the centre of local urban life for many years (Brambilla et al, 2007). Therefore, the historic urban environment contains the most historic information and cultural heritage, which must be preserved and carefully considered in urban planning and retrofitting.

The historic city centers are typical urban spaces. A number of studies on the soundscape and acoustic characteristics of the historic environment in urban spaces have been conducted. The description, evaluation and basic elements of the soundscape in urban open public space and the factors that affect its evaluation have been examined (Kang, 2003; Zhang and Kang, 2007). The urban sounds of European towns in early times has been studied and described as a semiotic system and an important component of community identity (Garrioch, 2003). The acoustic environment of the historic centre of Cáceres (Spain) was studied, and it was found that vehicles, passers-by and other individuals made the major contributions to the area's sound energy (Barrigón et al, 2013). Additionally, the relationships between measured sound levels and the way residents perceive noise were identified. Two typical noise sources were found: traffic and garbage trucks (Escobar et al, 2012). The subjective assessment of soundscape with local residents in historic areas has also been studied, and the conclusion was that local people are the most important audience (Wen et al, 2009). In a comparison study of the soundscape of two historic city centres with similar scales but different cultures, it was found that despite the cultural differences, there were similarities in the soundscapes as a result of homogeneous globalisation human activities. These activities can endanger local 
Lingjiang Huang \& Jian Kang: Sound Environment and Soundscape Preservation doi:10.1068/b130073p cultural identities and characteristics (Brambilla et al, 2007) and represent a problem common to all historic city centres.

Rapid urban transition has been considered for many years to be a threat for the traditional city centre with most of the its ancient heritage (Nijkamp, 1987), and the changes make to the sound environment in historic city centres reflects modernisation in addition to the change of urban image. It has been demonstrated that sound events from motorcycles might still have negative effects on perception in historic streets despite their relatively low sound levels (Brambilla and Maffei, 2010) and that soundmarks were often overcome by the high-intensity traffic noise (Marletta et al, 2007). In terms of soundscape design, it is proposed that it will be key for the identification and management of the 'wanted' and 'unwanted' sounds in the sound environment (Axelsson, 2011).

With the UNESCO world heritage site of the Johkang temple, the historic city centre of Lhasa is a typical and rare historic environment with rich and significant Tibetan cultural and religious characteristics, including its distinctive sound environment and sound sources. However, through modernisation, the cities are also facing the threat of change. Consequently, a change in a sound environment could lead to the change of people's perceptions and understanding them in context. Perceptions are the understanding of the sound environment and preservation of soundscape is of significant importance.

This study therefore aims to investigate the relationship between sound and urban space in the historic city centre of Lhasa and identify the sound sources as well as their cultural meanings by sound taxonomy. The paper also aims to analyse the temporal and spatial distributions of the sound environment, considering physical properties such as sound pressure level (SPL) and spectrum. A series of measurements, including soundwalks and fixed-point measurements, were performed along typical routes and at certain sites that best represented the sound environment in this area. Moreover, this paper compares the sound environment of Lhasa's historic centre with that of other historic centres and squares, aiming at providing suggestions and general principles for soundscape preservation in historic city centres. 
Lingjiang Huang \& Jian Kang: Sound Environment and Soundscape Preservation doi:10.1068/b130073p

This paper starts with the description of the study area and then analyses the relationship between urban spaces and sounds. This is followed by a description of the field measurement method and results. Finally, the paper compares the sound environment of Lhasa's historic centre with those of other cities and discusses soundscape preservation principles.

\section{Study Area}

\subsection{Introduction of the historic city centre of Lhasa}

Lhasa is the largest city in Tibet. The city has approximately 1400 years of history and possesses rich and significant Tibetan cultural and religious characteristics. Because of a strong religious tradition, a preservation policy, and slow economic development, the historic city centre maintains most of the historic urban fabric and has not experienced serious modern impact to date. Additionally, the city centre maintains many of its historic functions, such as trade, residence and religion. More importantly, most local Tibetan residents in the historic centre continue to practice traditional religious activities and folk customs, such as turning sutra wheels and making pilgrimages. Thus, with its well-preserved sound environment and cultural identity, Lhasa's historic city centre, as shown in Figure 1, could be regarded as a 'living fossil' of the traditional Tibetan city. Moreover, the urban sound environment of Lhasa's historic centre still contains historic meanings that reflect the traditional Tibetan social life and human activities. Thus, the soundscape should be regarded as an important urban cultural artefact in addition to the historic buildings and monuments and should be investigated, recorded and preserved. 


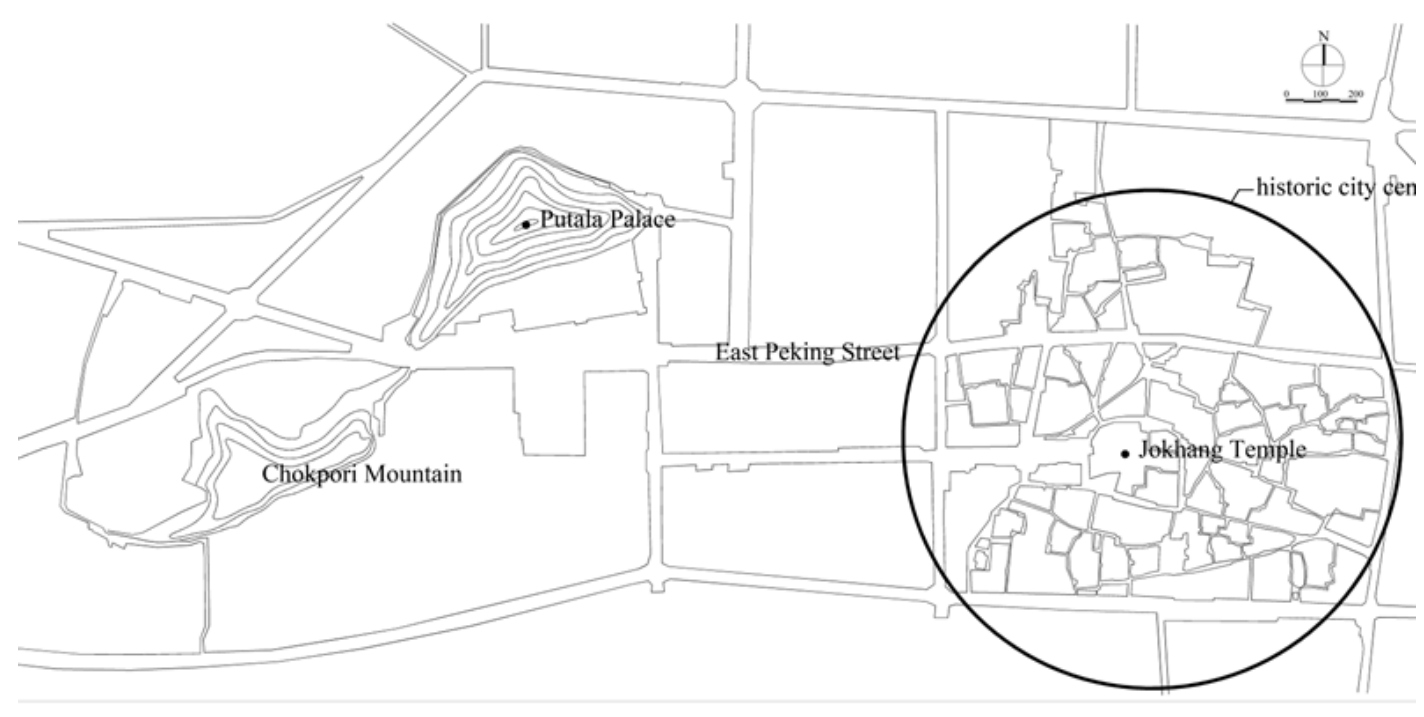

Fig.1. Map of the historic city centre and its location in Lhasa (Redrawn according to Knud L and Amund S, 2005)

Lhasa's historic city centre is of special importance to Tibetan pilgrims because they spend most of the daytime turning sutra wheels and praying in this area. Consequently, they spend most of their time in the sound environment, to which they also contribute. That is, they are the primary listeners to and participants in the area's historic soundscape. However, as a result of the development of tourism, a large tourist population joins in the sound environment, which has brought changes to the historic soundscape.

Because soundscape refers to the acoustic environment as perceived and understood by people in context (Kang, 2007), both the physical properties of the sound environment and the social and cultural factors of the users are of importance in understanding and preserving the soundscape in Lhasa's historic city centre.

\subsection{Sutra turning and Lhasa's historic urban form}

Historically and presently, religion is not confined to the monasteries but plays an important role in the daily life of Tibetans. It inhabits every aspect of social life and local customs and has a substantial influence on urban form and development as described below.

Unlike other Chinese historic cities, which were planned according to Confucianism, 
Lhasa was planned according to Tibetan religious beliefs and developed around the central Jokhang temple in a manner similar to traditional European cities, which developed around central churches (Yin, 2009). The site and construction of the Jokhang temple was determined according to religious considerations, with the result that the Jokhang temple became the city's most important holy building (Zhang and Chen, 2007).

The Tibetan religion is based on two important concepts: centralisation and transmigration. According to centralisation, a special building could be awarded holy significance and regarded as the centre of a specific area. This concept is expressed by pilgrims circling around a certain centre (Huang and Liu, 2010). Based on this special religious belief, ways and paths around specific buildings and areas were regulated as the sutra turning routes for pilgrims to follow.

Sutra turning has had a great influence on Lhasa's spatial formation. Because the Jokhang temple was regarded as Lhasa's primary holy centre, the path around the building gradually became a pilgrim route. The route is referred to as the 'Bakor', which means path 'around the temple'. The later urban expansion proceeded according to this concept and started from the 'Bakor'. The growth of the population later improved commercial development in this area and resulted in the establishment of many shops, which have lasted to the present. The area around the Jokhang temple became the centre of religion and trading as well as the main residential area. This process represents the primary urban development dynamic of ancient Lhasa, which was based on religious belief.

Figure 2 shows the urban map of Lhasa in different periods from A.D. 1000 until 2010. It can be observed that the urban pattern of Lhasa's historic centre was preserved as the city continued to grow.

\section{Urban Space and Sound}

Similar to most historic city centres, Lhasa's is a noisy location as a result of activities associated with commerce, religion and tourism. However, the diverse sound sources in the city centre have special characteristics, such as a regular pattern of occurrence, which relate to the local social life and the particularities of the urban space. Certain Environment and Planning B: Planning and Design 2015, Volume 42, Pages 652—674 
sounds have specific purposes or meanings that are of significance in this area.

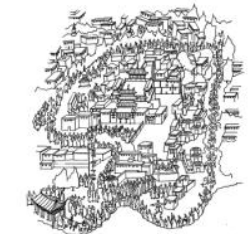

A.D. 1000

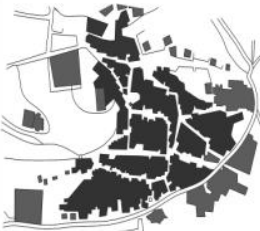

1904

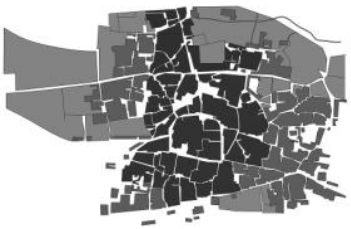

1955

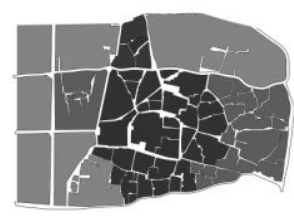

2010

$\stackrel{0100200300}{=}$

\subsection{Urban space}

The activities in the city centre can be principally categorised as religion, residence, trading and tourism. Typically, these activities occur in separate urban areas dedicated to religion, commerce or residence, as shown in Figure 3. However, in Lhasa, these spaces generally mix or overlap with one another rather than being distinct.

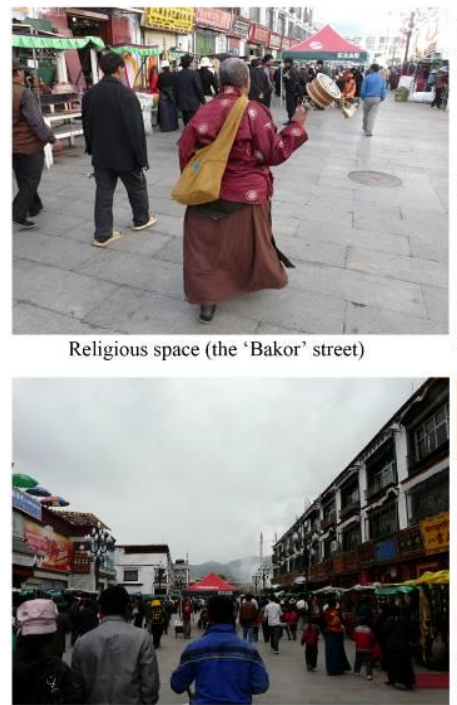

Commercial space (the 'Bakor' street)

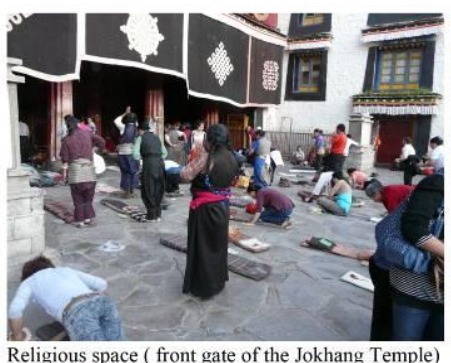

Religious space ( front gate of the Jokhang Temple)

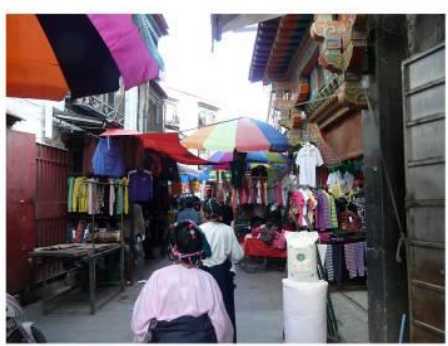

Commercial space (local commercial market)
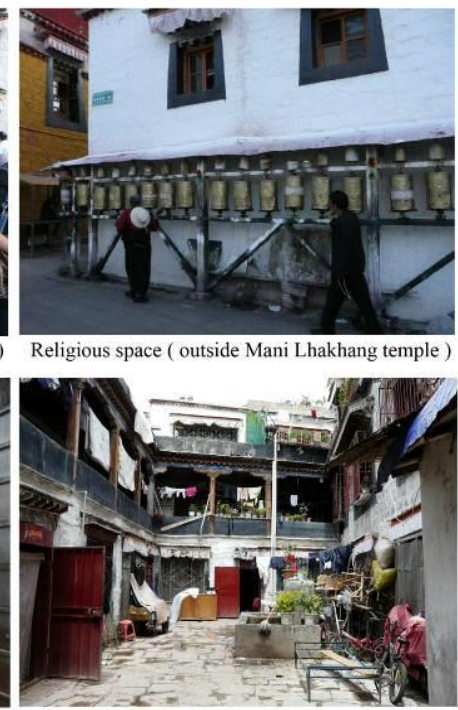

Residential space (compound )

Fig. 3. Typical urban spaces in the historic city centre

(1) Religious space. The 'Bakor' street is the main pilgrim route and the largest public religious space. On this street, pilgrims can worship by prostrating themselves or reciting the mantra while turning the wheel. The length of the street is 1200 meters with a width of 5 to 6 meters. The front gate of the Jokhang temple and the outside area of 
each temple with prayer wheels are also public religious spaces. It is the most distinctive characteristic of Tibetan urban open space that this space is used for worship as well.

(2) Commercial space. The second function of the 'Bakor' street is that of a shopping street for tourists. The street has double layers of shops. The first storeys of the buildings that face the main street and alleys are used as storefronts. Secondary stalls are arranged along the street or in a designated area as open markets. Another commercial street is primarily for local residents.

(3) Residential space. The main form of residence is a compound with a courtyard. The gate of the courtyard opens to the side alley, whereas the first floor of the building, which is on the commercial street side, is used as a storefront.

The urban fabric of this area consists of labyrinthine alleys and streets that centripetally surround the Jokhang temple. The historic buildings are primarily 2 or 3 storeys. The exterior walls are constructed of stones painted white with glass windows and hanging billboards, both of which are good sound reflection surfaces. Vegetation can be rarely found on the street or in the square. The pavement is flat, smooth dressed stone. This area is restricted to pedestrians and human-powered delivery tricycles, and during the daytime, vehicular traffic is strictly limited. There are no footpaths, and the pedestrians and the tricycles must share the street.

Because the area serves the mixed purposes of religion and commerce, the sound environment in the historic centre consists of diverse sound sources, including speech, the clip-clop sound of footsteps, children playing and religious activities. The various sounds occur and temporally and spatially overlap with the various corresponding activities. In different parts of the district and during different periods, distinct sounds may dominate the sound environment as soundmarks or the only sound may be ambient. Most of the urban public space in the district consists of pedestrian streets and alleys, and the sounds produced in these spaces could be amplified by multiple reflections. 
Lingjiang Huang \& Jian Kang: Sound Environment and Soundscape Preservation doi:10.1068/b130073p

\subsection{Sound taxonomy}

Sound taxonomy is important for understanding a space's sound environment (Brown et al, 2011). Some of the human (i.e., voices) or human-made sounds communicate distinct meanings or other information and are of significance to the soundscape of Lhasa's historic city centre. The sounds in the city centre include the human voice, natural sounds and the sounds of religious activities. It is essential to identify and comprehend these meaningful sounds to understand the soundscape in this area. Based on the authors' initial observation of the authors, main sounds were identified, including ambient sound, informative sounds, religious sounds, natural sounds and traffic noise (Figure 4). The qualitative description of these sounds is provided below, and a rigorous method that was designed to facilitate more detailed and qualitative analysis is presented in Section 4.

\section{(1) Ambient sound}

A large number of pedestrians, including pilgrims and tourists, move about in the historic centre each day at the height of the tourism period, particularly in the 'Bakor' street. The activities of the crowd contribute most to the ambient sound, of which voices and the clip-clop sound of footsteps are the most frequently heard in all areas. These sounds can be regarded as the main components of this area's ambient sound. 
Lingjiang Huang \& Jian Kang: Sound Environment and Soundscape Preservation doi:10.1068/b130073p

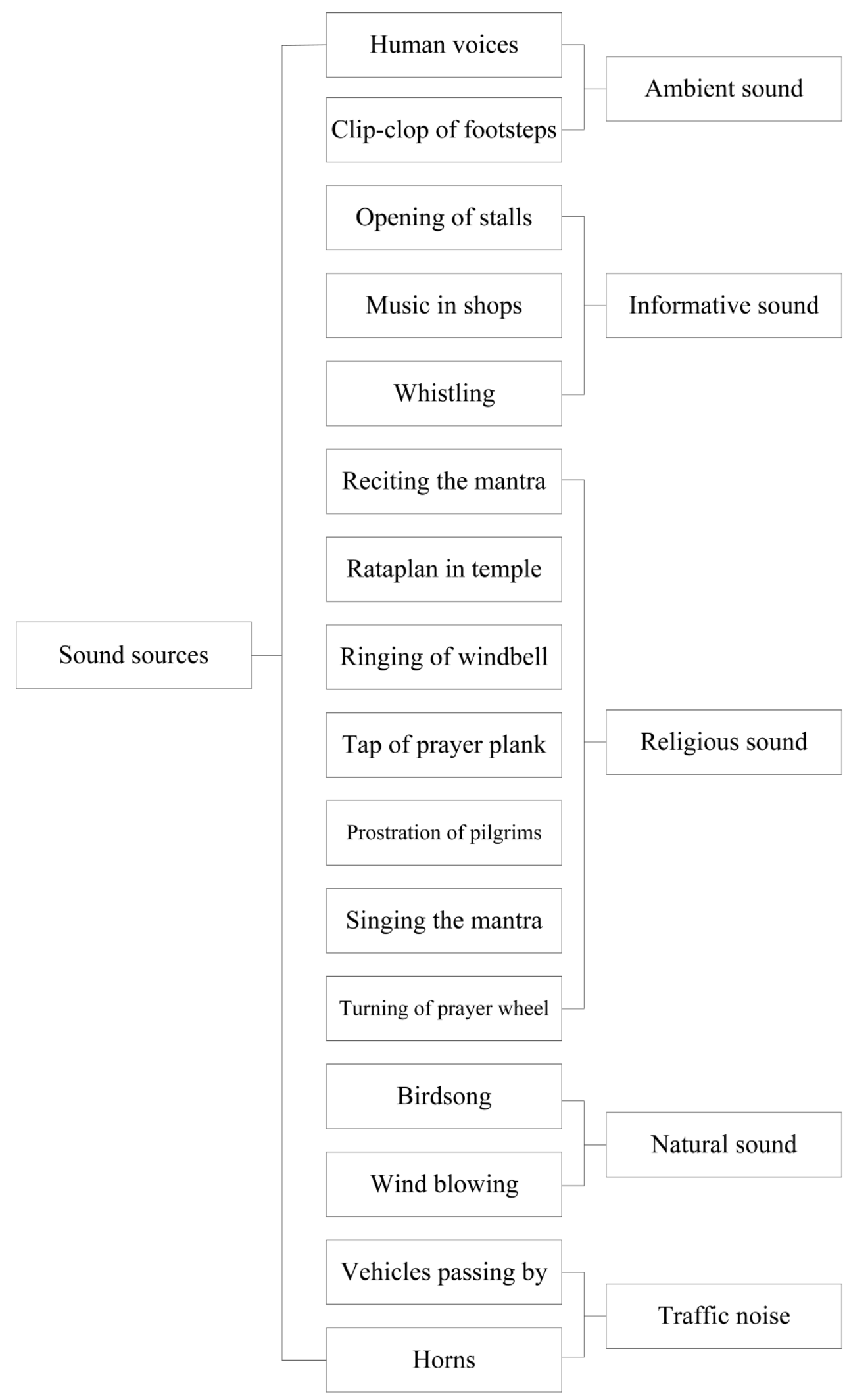

Fig. 4. Sound sources in the historic city centre of Lhasa 
(2) Informative sounds

'Informative sounds' refers to sounds that contain information for listeners. The sound of the opening of the stalls exhibits the most easily recognisable identity. This sound regularly occurs twice a day and announces the beginning and the end of trading activity. Because trade is one of the district's primary functions, the sound marks when a day's work begins and ends and thus the passing of a day. In this respect, the sound of the storefronts opening plays a role similar to that of bells in early European towns, which marked the passing of time (Garrioch, 2003).

Music in shops is used for the commercial purpose of attracting customers and thus represents a type of informative sound. Typically, popular music is used rather than traditional Tibetan folk songs. The music is louder than cries and used only to attract attention. Music is often used in the local commercial market, but in shops along the 'Bakor' street pilgrim route, music is only occasionally used.

Whistling is used by the drivers of the human-powered tricycle to warn pedestrians. The human-powered tricycle has replaced horse-drawn wagons and carriages. Correspondingly, the clip-clop sound of horse hooves and the cries of coachmen have been replaced by whistling. This is an informative sound that has considerably fewer negative effects than the sound of vehicle horns.

\section{(3) Religious sounds}

The sounds of traditional religious activities in the city centre display strong cultural characteristics. In Tibetan Buddhism, a number of worship ceremonies are typically conducted outdoors, which means that religious sounds can be regularly heard in urban open spaces in addition to inside the temples. As a result of the variety of religious activities, different religious sounds are produced that have their respective meanings and significance for the soundscape and the acoustic community in this area.

Some of the sounds contribute to shaping the acoustic community, such as reciting the mantra, the rataplan in the temple and the ringing of wind bells, whereas certain 
sounds announce their acoustic identities, such as the tapping of a plank during prayer. Meanwhile, some of the religious sounds occur regularly; for example, the rataplan occurs in the early evening, and singing the mantra occurs when the pilgrim completes a certain distance. The time that certain sounds occur indicates types of traditional activities.

The recital of the mantra involves the sound of a human voice. However, this sound differs substantially from and is more meaningful than general speech. Tibetans are accustomed to reciting the mantra while turning prayer wheels along the pilgrim route. Another case is that local beggars also recite the mantra loudly during begging while sitting cross-legged by the wall. The sound of the voice is continuous, and typically the words are spoken much more rapidly and rhythmically than in normal speech. Moreover, the sound is generally louder than speech and can be heard clearly. This sound helps to maintain the spiritual community of religion because a large number of passing pilgrims recite the mantra together. For individual pilgrims, reciting the mantra also indicates their identity as Buddhists and helps them to be recognised in this community. Additionally, it is important for the subjective evaluation of the sound environment when the sound activity is related to the individual (Yang and Kang, 2003).

The ringing of wind bells is distinctly audible and has the most distinct relationship to the shape of the urban space because the bells are installed on the roof corners of certain temples in the district. The wind bells are activated whenever there is wind, and the sound is a reminder of religious authority. The area that the bell sound can cover is determined by the distribution of the temples and spatially defines the religious community.

The rataplan in the temple on the 'Bakor' street has regular rhythms and cadence. Although drumming is only used indoors during the daily worship ceremony for the local community during certain periods, its sound can be clearly heard outside during normal working days. This sound serves as an acoustic identity for the spiritual community, similar to the ringing of church bells. Furthermore, the sound delivers temporal information to the community residents during the pilgrimage and helps to create the sense of belonging. 
Prayer wheels are a group of copper buckets lined inside or around the outside walls of a temple. Turning the prayer wheels is a procedure accompanied with praying. The pilgrims produce a distinct sound by continuously pushing them, and the sound can last all day.

The prostration of the pilgrims produces a series of sounds, such as that produced by the friction between the body and the ground. The complete prostration involves specific procedures that produce a regular rhythm and short, vibrant sounds. Normally, prostrations are conducted crowds of pilgrims at the front gate of the Jokhang temple as the designated site. Because the Jokhang temple is the most holy space in the district, the sounds produced and allowed at this site represent a type of authority and shape the sense of community, not only for the Tibetan residents of this district but also for all of the pilgrims who visit Lhasa. Furthermore, these sounds have two functions: to indicate authority and to provide spatial orientation. That is, the sounds reflect the religious authority of the Jokhang temple when they are produced by a large group of individuals devotionally and in conformity with tradition. Additionally, the sounds are audible spatial marks that shape people's sense of the urban space.

Singing the mantra is a key part of the long-form prostration that is conducted individually by each pilgrim along the pilgrim route in the form of day-long singing worship. This sound is the most audible in the historic centre. It occurs periodically with unique rhythms and in high-pitched voices, and it can be regarded as the holy song. The singing of the mantra communicates the contents of religion to all nearby listeners and strengthens the holy meaning of the Jokhang temple. The sound source is moving and continuous in time. Thus, this sound affects more areas in the district.

(4) Natural sounds

Natural sounds, such as the wind and birdsong, can be heard only in certain peaceful and quiet locations. These sounds are of less significance in the overall sound environment of the historic city centre. However, they might be regarded as a sign for distinguishing between noisy (or lively) and quiet urban spaces. 


\subsection{Change in sound environment}

Compared with the ancient historic urban sound environment, there have been changes in the present sound environment. First, the same sounds may have different meanings for different listeners. For example, meaningful sounds cannot evoke a sense of community among tourists. Second, traditional goals can be achieved by new sounds. For example, street cries are replaced by music, and the cries of coachmen that once warned pedestrians have been replaced by whistling. Third, certain sounds have been lost as a result of changing times, such as the clip-clop of horse hooves and the noises of animals.

However, some of the meaningful sounds have been preserved in their traditional appearance, such as singing the mantra and the rataplan in temples, which provide the opportunity to experience and understand the historic urban soundscape and the characteristics of the traditional culture from the aspect of sound. In addition, they help tourists to experience the 'authenticity' of the historic place (Erendil and Zuhal, 2002).

Overall, it can be observed that sound sources are related to daily life in various urban spaces. A system of sound sources exists in the historic city centre; some sound sources have lasted for centuries in their traditional form and are important in shaping the acoustic community. Together, these sounds construct the unique sound environment of Lhasa's historic city centre and shape the sense of the local community, the urban space and religious beliefs.

\section{Field Measurement}

\subsection{Method}

To understand the sound environment in the historic centre of Lhasa, soundwalks and fixed-point measurements were conducted for the ambient sound, and fixed-point measurements were also conducted for soundmarks.

The soundwalk measurements were of three typical pedestrian routes, a pedestrian square and the main street in Lhasa with motor-vehicle traffic. A fixed-point Environment and Planning B: Planning and Design 2015, Volume 42, Pages 652-674 
Lingjiang Huang \& Jian Kang: Sound Environment and Soundscape Preservation

doi:10.1068/b130073p

measurement was conducted in a residential compound. The soundwalk routes and the fixed-point site are shown in Figure 5, and the description of each soundwalk measurement is shown in Table 1.

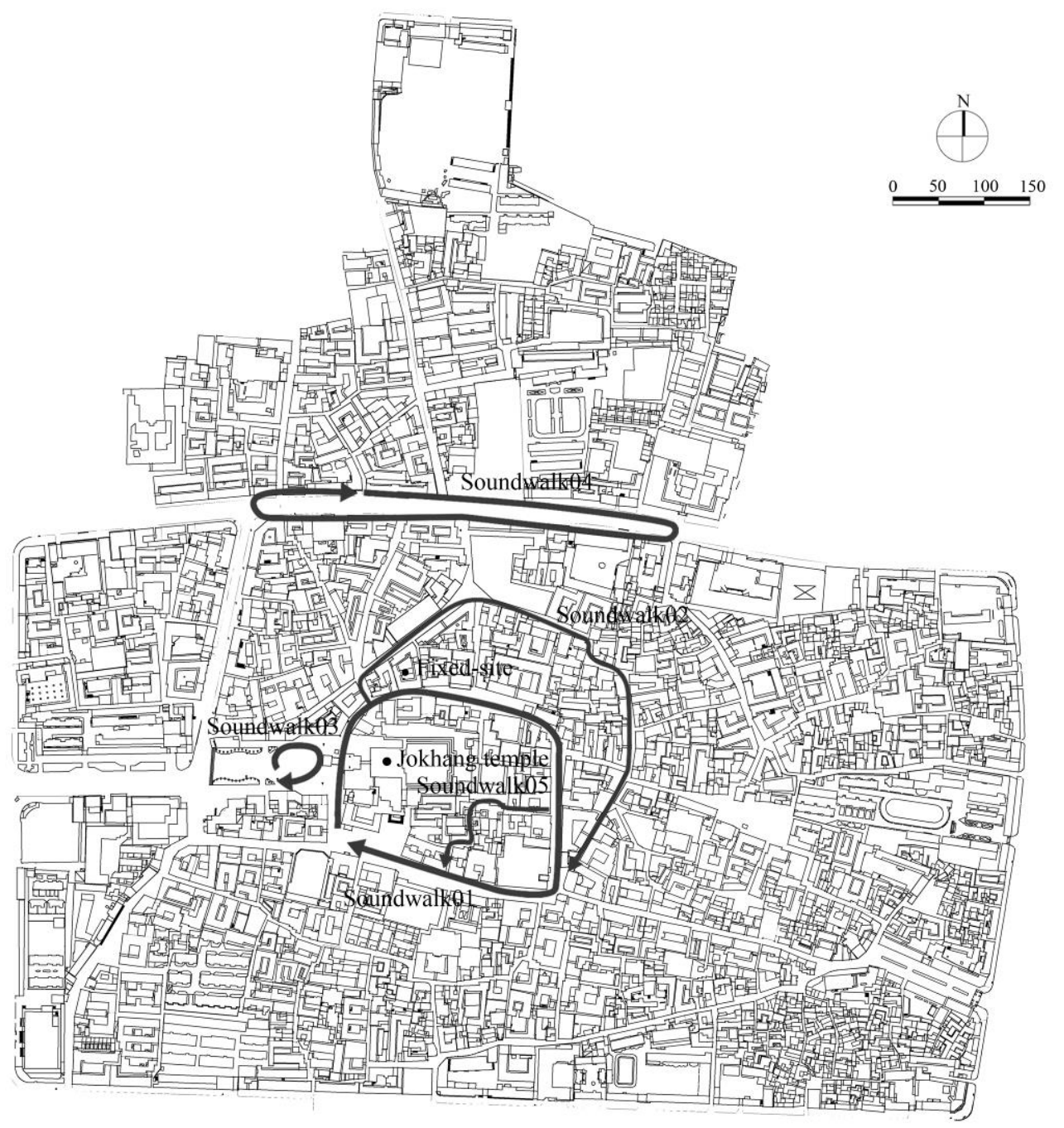

Fig. 5. Soundwalk routes and the site for the fixed-point measurement

Table 1. Description of soundwalk routes

\begin{tabular}{|c|c|c|c|}
\hline $\mathrm{NO}$ & Name & Description & $\begin{array}{l}\text { Measuring } \\
\text { period }\end{array}$ \\
\hline $\begin{array}{c}\text { Soundwalk } \\
01\end{array}$ & 'Bakor' street & $\begin{array}{l}\text { This route is the main historic pilgrimage and } \\
\text { commercial street around the Jokhang temple. During } \\
\text { daytime, the street is restricted to pedestrians and } \\
\text { contains the majority of pilgrims, tourists and } \\
\text { merchants. The length of the route is approximately } \\
1200 \text { meters. }\end{array}$ & $\begin{array}{l}\text { Morning } \\
8: 00-8: 15 \\
\text { Noon } \\
\text { 12:00-12:15 } \\
\text { Evening } \\
\text { 22:00-22:15 }\end{array}$ \\
\hline
\end{tabular}


Lingjiang Huang \& Jian Kang: Sound Environment and Soundscape Preservation

doi:10.1068/b130073p

\begin{tabular}{|c|c|c|c|}
\hline $\begin{array}{c}\text { Soundwalk } \\
02\end{array}$ & $\begin{array}{l}\text { local } \\
\text { commercial } \\
\text { market street }\end{array}$ & $\begin{array}{l}\text { This route is the local historic commercial market, } \\
\text { which was formed during the Qing Dynasty, and is for } \\
\text { pedestrians only, including local residents and tourists. } \\
\text { The length of the route is approximately } 545 \text { meters. }\end{array}$ & $\begin{array}{l}\text { Morning } \\
8: 00-8: 15 \\
\text { Noon } \\
\text { 12:00-12:15 } \\
\text { Evening } \\
22: 00-22: 15\end{array}$ \\
\hline $\begin{array}{c}\text { Soundwalk } \\
03\end{array}$ & $\begin{array}{l}\text { Jokhang } \\
\text { temple square }\end{array}$ & $\begin{array}{l}\text { The square is in front of the Jokhang temple. It was } \\
\text { built in 1985, to distribute the crowds. The width of } \\
\text { the square is approximately } 60 \text { meters, and the area is } \\
\text { approximately } 4000 \mathrm{~m}^{2} \text {. }\end{array}$ & $\begin{array}{l}\text { Morning } \\
8: 40-8: 45 \\
\text { Noon } \\
\text { 13:17-13:23 } \\
\text { Evening } \\
21: 30-21: 35\end{array}$ \\
\hline $\begin{array}{c}\text { Soundwalk } \\
04\end{array}$ & $\begin{array}{l}\text { East Peking } \\
\text { Street - } \\
\text { main traffic } \\
\text { street }\end{array}$ & $\begin{array}{l}\text { This is Lhasa's main traffic street. The width of the } \\
\text { street is } 25 \text { meters, and the buildings are } 2-3 \text { storeys. } \\
\text { The length of the route is approximately } 425 \text { meters. }\end{array}$ & $\begin{array}{l}\text { Morning } \\
8: 30-08: 50 \\
\text { Noon } \\
11: 25-11: 40 \\
\text { Evening } \\
22: 50-23: 00\end{array}$ \\
\hline $\begin{array}{c}\text { Soundwalk } \\
05\end{array}$ & $\begin{array}{l}\text { historic } \\
\text { residential } \\
\text { alley }\end{array}$ & $\begin{array}{l}\text { This route is an alley inside the residential zone of the } \\
\text { city centre and was selected to study the quietness of } \\
\text { the area. The length of the route is approximately } 170 \\
\text { meters. }\end{array}$ & $\begin{array}{l}\text { Noon } \\
\text { 12:45-12:55 } \\
\text { Evening } \\
\text { 22:00-22:05 }\end{array}$ \\
\hline
\end{tabular}

Soundwalks 01 and 02 covered the core area of the historic centre and all of the sounds discussed above were included. Soundwalk 03 was selected to understand the acoustic environment of the open space in this area, which is also the transition zone between the historic and the modernised areas. Soundwalk 04 was selected to analyse the sound environment with motor-vehicle traffic. Soundwalk 05 and the fixed-point site were selected to study the quietness in this area.

Overall, the routes were selected according to the principle of best representing the urban spatial characteristics, the daily activity and the sound environment of a given area. The walking pace of each route was maintained as equally as possible, whereas the duration of each walk varied according to the length of each route. According to Tibetan religious regulations, the sutras should be turned clockwise. Similarly, the crowd of pedestrians moves in a clockwise direction. Therefore, the soundwalks were 
Lingjiang Huang \& Jian Kang: Sound Environment and Soundscape Preservation

doi:10.1068/b130073p

performed clockwise. The soundwalks were conducted along selected routes during three periods of a normal day during the tourism period: morning, noon and evening. The soundmarks were measured using fixed-point measurements near the sound sources.

The instrument of measurement was a SvanPC+, which measures and records sounds continuously at $10 \mathrm{~s}$ intervals using handheld equipment. The microphone is covered with a windshield. In the meantime, sound signals were also recorded with a video recorder (Panasonic DMC-FZ18) .

\subsection{Sound sources}

The occurrence of sound sources in the soundwalk measurements is shown in Table 2, in terms of the sounds heard by the two observers but also by listening to the recorded signals. It can be observed that all of the sound sources in the sound system shown in Figure 4 could be heard during the measurement periods, and the sounds of voices occurred most frequently during all of the soundwalks. However, the sound of footsteps could only be heard on certain soundwalk routes (the observers walked with soft shoes so that their footsteps would not be taken into account). 
Lingjiang Huang \& Jian Kang: Sound Environment and Soundscape Preservation

doi:10.1068/b130073p

Table 2. Occurrence of sounds during soundwalk measurements

\begin{tabular}{|c|c|c|c|c|c|c|c|c|c|c|c|c|c|c|c|}
\hline \multirow{2}{*}{\multicolumn{2}{|c|}{ Sounds }} & \multicolumn{3}{|c|}{ Soundwalk 01} & \multicolumn{3}{|c|}{ Soundwalk 02} & \multicolumn{3}{|c|}{ Soundwalk 03} & \multicolumn{3}{|c|}{ Soundwalk 04} & \multicolumn{2}{|c|}{ Soundwalk 05} \\
\hline & & morning & noon & evening & morning & noon & evening & morning & noon & evening & morning & noon & evening & noon & evening \\
\hline \multirow{6}{*}{ 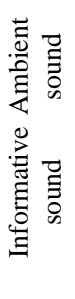 } & Human voices & $\sqrt{ }$ & $\sqrt{ }$ & $\sqrt{ }$ & $\sqrt{ }$ & $\sqrt{ }$ & $\sqrt{ }$ & $\sqrt{ }$ & $\sqrt{ }$ & $\sqrt{ }$ & $\sqrt{ }$ & $\sqrt{ }$ & $\sqrt{ }$ & $\sqrt{ }$ & $\sqrt{ }$ \\
\hline & Clip-clop of footsteps & $\sqrt{ }$ & $\sqrt{ }$ & $\sqrt{ }$ & & & & $\sqrt{ }$ & $\sqrt{ }$ & $\sqrt{ }$ & & & & $\sqrt{ }$ & $\sqrt{ }$ \\
\hline & Opening of stalls & $\sqrt{ }$ & & $\sqrt{ }$ & $\sqrt{ }$ & & $\sqrt{ }$ & & & & & & & & \\
\hline & Music in shops & & $\sqrt{ }$ & & $\sqrt{ }$ & $\sqrt{ }$ & $\sqrt{ }$ & & & & & & $\sqrt{ }$ & & \\
\hline & Whistling & $\sqrt{ }$ & & $\sqrt{ }$ & & $\sqrt{ }$ & & & & & & & & & \\
\hline & Reciting the mantra & $\sqrt{ }$ & & $\sqrt{ }$ & & & & $\sqrt{ }$ & $\sqrt{ }$ & $\sqrt{ }$ & & & & & \\
\hline \multirow{6}{*}{ 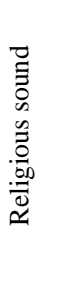 } & Rataplan in temple & & & $\sqrt{ }$ & & & & & & & & & & & \\
\hline & Ringing of wind bells & $\sqrt{ }$ & $\sqrt{ }$ & & & $\sqrt{ }$ & & & & & & & & & \\
\hline & Tap of prayer plank & $\sqrt{ }$ & $\sqrt{ }$ & & & & & & & & & & & & \\
\hline & Prostration of pilgrim & $\sqrt{ }$ & $\sqrt{ }$ & & & & & & & & & & & & \\
\hline & Singing the mantra & & $\sqrt{ }$ & & & & & & & & & & & & \\
\hline & Turning of prayer wheels & $\sqrt{ }$ & $\sqrt{ }$ & $\sqrt{ }$ & & & & & & & & & & & \\
\hline \multirow{2}{*}{ 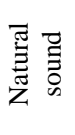 } & Birdsong & $\sqrt{ }$ & & & & & $\sqrt{ }$ & & & & & & & $\sqrt{ }$ & \\
\hline & Wind blowing & & & & & & $\sqrt{ }$ & & & & & & & $\sqrt{ }$ & \\
\hline \multirow{2}{*}{ 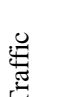 } & Vehicles passing by & & & & & & & & & & $\sqrt{ }$ & $\sqrt{ }$ & $\sqrt{ }$ & & \\
\hline & Horns & & & & & & & & & & $\sqrt{ }$ & $\sqrt{ }$ & $\sqrt{ }$ & & \\
\hline
\end{tabular}


Religious sounds could be heard on a limited number of soundwalk routes and in a limited number of periods. For example, a voice reciting the mantra could be clearly identified only on Soundwalks 01 and 03. Music from loudspeakers in shops could be heard on Soundwalks 01, 02 and 04. Intensive traffic noise was only heard during Soundwalk 04. The natural sounds of birdsong and wind were the least frequently heard and only occurred during Soundwalk 05.

High-frequency sounds, such as whistles and the ringing of wind bells, could be heard in the daytime during Soundwalks 01 and 02. Of all of the soundwalks, Soundwalk 01 contained most of the sound sources, particularly in the morning and at noon.

It is easy to understand that the small number of passers-by and the louder traffic noise during Soundwalk 04 were the main reasons the sound of footsteps was barely discernible. However, there are two reasons that no footsteps were heard during Soundwalk 02. First, the street on which the Soundwalk 02 measurement was conducted is much narrower than that of Soundwalk 01. Thus, the crowd moved substantially more slowly, and there was little footstep sound. Second, the music played in the shops could be heard during all of the periods. Thus, the sound of the music masked most of the footstep sounds. The natural sounds of birdsong and wind could only be heard during Soundwalk 03, which indicates the quietness of the location.

Overall, it can be said that the sound sources display a highly distinct spatial and temporal distribution. The sound of voices occurs on all of the routes and during all of the periods, and the recital of the mantra can be clearly heard. The ringing of wind bells can be identified among the background sounds. Various religious sounds continue to be produced in their traditional way and appear frequently on Soundwalk 01 along the 'Bakor' street, such as the sound of pilgrims singing the mantra and the rataplan in the temple, which represent the traditional religious identities. As a result, the sound environment has been preserved with its original and traditional characteristics over centuries and resembles the sound environment of ancient times.

Some of the sounds correspond to certain traditional activities and contain local characters with historic cultural identities. Four sounds can be identified accordingly Environment and Planning B: Planning and Design 2015, Volume 42, Pages 652-674 
doi:10.1068/b130073p

as soundmarks in this area: the prostration of the pilgrims at the Jokhang temple gate, the rataplan in the Mani Lhakhang temple, the turning of prayer wheels, and pilgrims singing the mantra. These sounds can be clearly heard during normal days and have been in this area for centuries. They are part of historic customs and are key sound sources. Table 3 describes each soundmark as well as the measurements.

Table 3. Description of soundmark measurements

\begin{tabular}{cllll}
\hline \multicolumn{1}{c}{ NO } & \multicolumn{1}{c}{ Sound source } & \multicolumn{1}{c}{ Location } & \multicolumn{1}{c}{ Activities } & \multicolumn{1}{c}{ Measurement point } \\
\hline Soundmark01 & Prostration of pilgrims & Front gate of the Johkang temple & Pilgrimage & At the edge of the crowd of pilgrims \\
Soundmark02 & Rataplan in the temple & Inside the temple & Sutra turning & 2 meters away from the temple gate \\
Soundmark03 & Turning of prayer wheels & Around the outside temple wall & Sutra turning & 2 meters away from the prayer wheel shelf \\
Soundmark04 & Singing the mantra & Along the Bakor street & Pilgrimage & 1 meter away from the pilgrims \\
\hline
\end{tabular}

\subsection{Soundmarks}

Table 4 shows the $\mathrm{L}_{\mathrm{eq}}$ (equivalent continuous sound level, used to examine the sound environment in terms of the average energy of sound during the measurement time) and $L_{n}$ (statistical noise levels, which indicate the level of noise exceeded for $n$ percent of the specified measurement period; $\mathrm{L}_{10}, \mathrm{~L}_{50}$ and $\mathrm{L}_{90}$ are used to indicate the intrusive, median and background sound levels, respectively) (Kang, 2007) of each soundmark, and the spectrum comparisons are given in Figure 6. In terms of A-weighted SPL, soundmark02 has the highest $\mathrm{L}_{\mathrm{eq}}(84.9 \mathrm{dBA})$,

Table 4. Measured $\mathrm{L}_{\mathrm{eq}}$ and $\mathrm{L}_{\mathrm{n}}$ of the soundmarks

\begin{tabular}{cccccc}
\hline Measurement & Weighting & $\mathbf{L}_{\mathbf{e q}}$ & $\mathbf{L}_{\mathbf{1 0}}$ & $\mathbf{L}_{\mathbf{5 0}}$ & $\mathbf{L}_{\mathbf{9 0}}$ \\
\hline Soundmark 01 & $(\mathrm{dBA})$ & 80.7 & 72.6 & 70.1 & 68.1 \\
& $(\mathrm{dBZ})$ & 85.6 & 77.2 & 75.3 & 73.6 \\
Soundmark 02 & $(\mathrm{dBA})$ & 84.9 & 79.6 & 68.5 & 61.3 \\
& $(\mathrm{dBZ})$ & 91.2 & 84.5 & 80.2 & 70.3 \\
Soundmark 03 & $(\mathrm{dBA})$ & 84.4 & 75.9 & 70.1 & 66.0 \\
& $(\mathrm{dBZ})$ & 95.2 & 88.7 & 84.4 & 81.5 \\
Soundmark 04 & $(\mathrm{dBA})$ & 82.3 & 74.2 & 70.6 & 65.1 \\
& $(\mathrm{dBZ})$ & 90.2 & 85.2 & 76.2 & 72.1 \\
\hline
\end{tabular}

soundmark03 the second highest ( $84.4 \mathrm{dBA})$, and soundmark01 the lowest $(80.7$ dBA). Although soundmark02's sound, namely, the drum, is inside the building, it still has the highest $\mathrm{L}_{\mathrm{eq}}$. However, it has the lowest $\mathrm{L}_{90}$, and the difference between $\mathrm{L}_{90}$ and 
$\mathrm{L}_{10}$ is $18.3 \mathrm{dBA}$, which indicates that it contains a sudden high-SPL sound, perhaps corresponding to the activity of rhythmic drumming. The activity that generates soundmark01 involves a number of participants, but this soundmark has the lowest $\mathrm{L}_{\text {eq }}$, as well as the lowest difference between $\mathrm{L}_{90}$ and $\mathrm{L}_{10}$, which is only $4.5 \mathrm{dBA}$. This indicates that soundmark01, corresponding to the activity of pilgrims' prostration, is much smoother. Overall, it seems that human sounds, including singing have prostration, have lower sound levels than those of instruments.

In terms of spectrum, the soundmarks show clear differences. Soundmark01 has its most energy at low and middle frequencies between $125 \mathrm{~Hz}$ and $500 \mathrm{~Hz}$, whereas Soundmark02 has high sound energy at lower frequencies between $63 \mathrm{~Hz}$ and $250 \mathrm{~Hz}$ and higher frequencies between $1 \mathrm{kHz}$ and $4 \mathrm{kHz}$. Soundmark03 has high sound energy at low frequencies, and the SPL decreases sharply as the frequency increases. The sound energy of soundmark04 is mostly between $250 \mathrm{~Hz}$ and $1 \mathrm{kHz}$, corresponding to the sound of human voices. Overall, all soundmarks have higher SPLs than those of the soundwalks, especially at low and high frequencies.

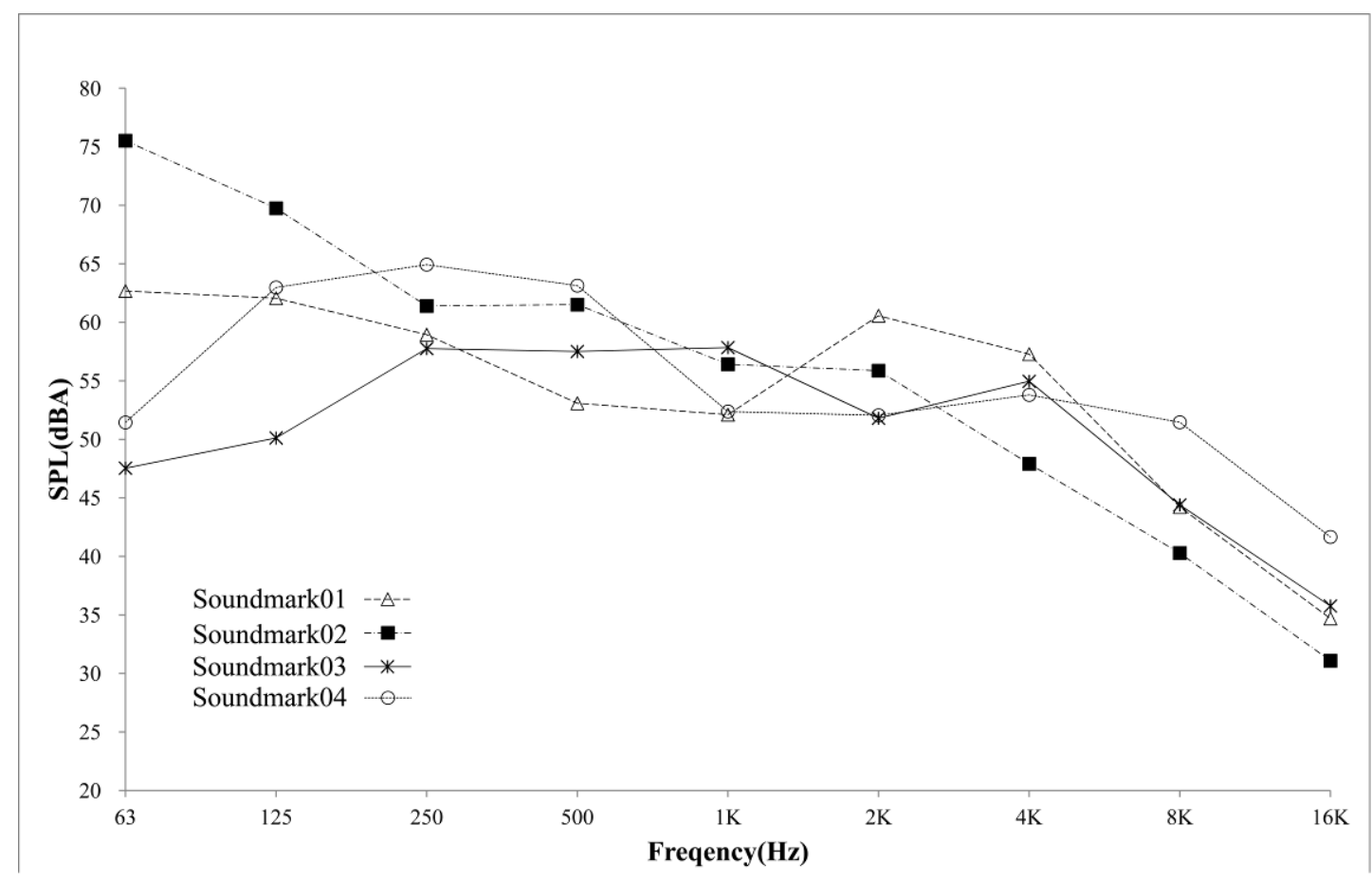

Fig. 6. Measured average spectrum of the four soundmarks 
Lingjiang Huang \& Jian Kang: Sound Environment and Soundscape Preservation

doi:10.1068/b130073p

In addition to SPL and spectrum, the source-receiver distance is also important for soundscape perception. Soundmark02 and soundmark03 are located in a small square of approximately $35 \mathrm{~m} \times 25 \mathrm{~m}$ on north 'Bakor' street, whereas soundmark01 is in a more open space of $140 \mathrm{~m} \times 60 \mathrm{~m}$, and soundmark04 moves in a much narrower street space with a high aspect ratio. Because these spaces all have similar boundary conditions of rough and uneven building façades and smooth ground, the spatial forms and proportions may have remarkable impacts on reverberation time and sound attenuation with source-receiver distance.

\subsection{Changes in the sound environment over time}

The changes in the SPL over time are shown in Figure 7. It can be observed that all of the soundwalks show significant fluctuations during the measurement periods, and sound peaks could be observed. The Soundwalk 01 SPL varies between $55 \mathrm{dBA}$ and 75 $\mathrm{dBA}$, and the sound peaks include human voices and religious sounds during all of the periods, and music from loudspeakers form some of the sound peaks during noon and evening. The Soundwalk 02 SPL varies between $55 \mathrm{dBA}$ and $75 \mathrm{dBA}$ for the most part. The SPL during the noon period has a narrower fluctuation range than during the morning and evening periods, which indicates that fewer sounds occurred during the noon period. Informative sounds, such as the music from shops' loudspeakers and the opening of the stalls, dominate the sound peaks during the morning and noon periods, whereas voices dominate during the evening period. The Soundwalk 03 SPL fluctuates between $55 \mathrm{dBA}$ to $70 \mathrm{dBA}$ during the morning and evening periods and between 60 $\mathrm{dBA}$ and $75 \mathrm{dBA}$ during the noon period. Most of the peaks are the sound of human voices. The Soundwalk 04 SPL exhibits the most significant fluctuations, between 65 $\mathrm{dBA}$ and $90 \mathrm{dBA}$ during the measurement period, and a number of peaks are over 90 dBA. Most sound peaks are traffic noise rather than other activities.

Table 5 shows the measured $\mathrm{L}_{\mathrm{eq}}$ and $\mathrm{L}_{\mathrm{n}}$ values. It can be observed that the Soundwalk $04 \mathrm{~L}_{\mathrm{eq}}$ with motor-vehicle traffic in the morning is $78.4 \mathrm{dBA}$, which is the highest of all of the measurements during all of the periods.

Regarding individual soundwalks in pedestrian areas, the noisiest period of Soundwalk 01 occurred during the morning period, of Soundwalk 02 during the noon 
period and of Soundwalk 03 during the noon period. The quietest period of each soundwalk occurred during the evening, morning and morning periods, respectively.

With regard to time, during the morning period, the noisiest area is Soundwalk 01, and during the noon and evening periods, it is soundwalk 02, whereas the quietest areas are Soundwalk 03 during the morning period and Soundwalk 01 during both noon and evening periods.

These results agree with the regularity of the actual activities that occurred during each soundwalk. That is, for soundwalk 02 and 03, the busiest hours were typically during the noon period, whereas during Soundwalk 01, the largest number of pilgrims appeared during the morning period. In Soundwalk 01, the sutra turning of the pilgrims stopped at evening. However, during the evening, the local daily life continued during Soundwalk 02, and tourists continued to move about during Soundwalk 03.

It is important to note that the $\mathrm{L}_{\mathrm{eqA}}$ of the alley during Soundwalk 05 and of the residential compound (i.e., the fixed-point measurement) were much lower, at 62.3 $\mathrm{dBA}$ and 54.6 dBA, respectively. Because the measurements were conducted during the busy hours of noon, the compound was the quietest location in this area, $14.8 \mathrm{dBA}$ lower than the nearest pedestrian route of Soundwalk 01 during the noon period. It can be concluded that the labyrinthine alleys act as effective sound barriers between the noisy commercial streets and the residential compounds. 
doi:10.1068/b130073p
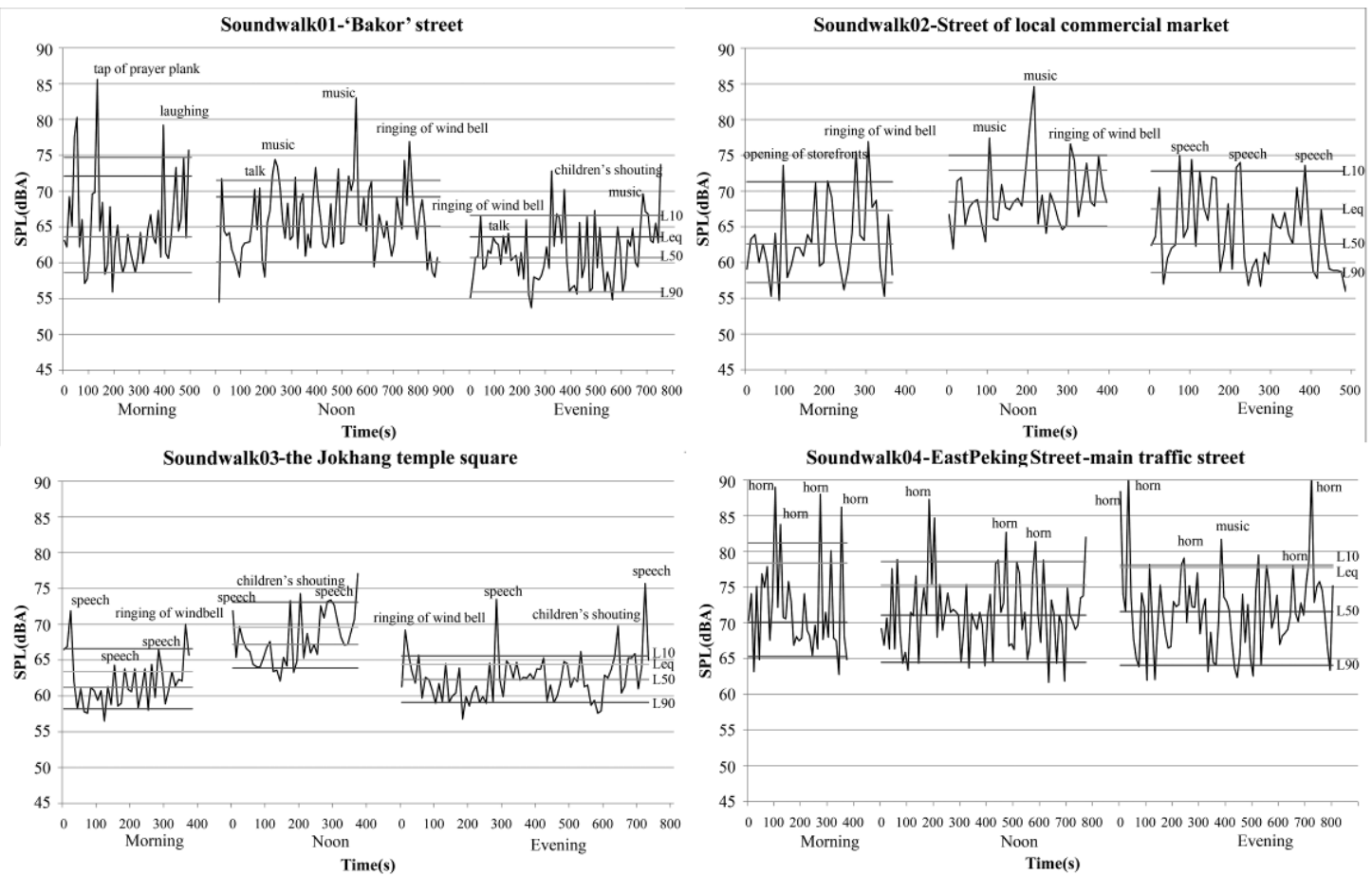

Fig. 7. Measurement of soundwalk SPLs over time

Table 5. Measured $L_{e q}$ and $L_{n}$ of the soundwalks

\begin{tabular}{|c|c|c|c|c|c|c|c|c|c|c|c|c|c|}
\hline \multirow[t]{2}{*}{ Measurement } & & \multicolumn{4}{|c|}{ Morning } & \multicolumn{4}{|c|}{ Noon } & \multicolumn{4}{|c|}{ Evening } \\
\hline & $(\mathrm{dBA})$ & $\begin{array}{l}\mathrm{L}_{\mathrm{eq}} \\
72.1\end{array}$ & $\begin{array}{l}\mathrm{L}_{10} \\
74.8\end{array}$ & $\begin{array}{l}\mathrm{L}_{50} \\
63.6\end{array}$ & $\begin{array}{l}\mathrm{L}_{90} \\
58.6\end{array}$ & $\begin{array}{l}\mathrm{L}_{\mathrm{eq}} \\
69.2\end{array}$ & $\begin{array}{l}\mathrm{L}_{10} \\
72.0\end{array}$ & $\begin{array}{l}\mathrm{L}_{50} \\
65.1\end{array}$ & $\begin{array}{l}\mathrm{L}_{90} \\
60.1\end{array}$ & $\begin{array}{l}\mathrm{L}_{\mathrm{eq}} \\
63.6\end{array}$ & $\begin{array}{l}\mathrm{L}_{10} \\
66.6\end{array}$ & $\begin{array}{l}\mathrm{L}_{50} \\
60.7\end{array}$ & $\begin{array}{c}\mathrm{L}_{90} \\
50.6\end{array}$ \\
\hline Soundwalk 01 & (dBZ) & 85.9 & 89.3 & 84.8 & 81.6 & 85.0 & 88.6 & 82.9 & 79.4 & 85.3 & 87.9 & 85.4 & 81.4 \\
\hline \multirow[t]{2}{*}{ Soundwalk 02} & $(\mathrm{dBA})$ & 67.3 & 71.3 & 62.6 & 57.2 & 72.9 & 75.0 & 68.5 & 65.1 & 67.5 & 72.8 & 62.6 & 58.6 \\
\hline & (dBZ) & 86.8 & 88.6 & 86.8 & 83.6 & 85.3 & 88.9 & 83.3 & 80.1 & 85.3 & 87.3 & 85.4 & 81.4 \\
\hline \multirow[t]{2}{*}{ Soundwalk 03} & $(\mathrm{dBA})$ & 63.4 & 66.6 & 61.2 & 58.2 & 69.6 & 73.1 & 67.2 & 63.9 & 64.4 & 65.6 & 62.3 & 59.1 \\
\hline & (dBZ) & 80.9 & 84.6 & 71.7 & 67.8 & 83.1 & 86.2 & 79.0 & 67.9 & 80.0 & 84.1 & 73.5 & 68.0 \\
\hline \multirow[t]{2}{*}{ Soundwalk 04} & $(\mathrm{dBA})$ & 78.4 & 81.2 & 70.1 & 65.3 & 75.3 & 78.6 & 71.1 & 64.5 & 77.7 & 78.1 & 71.6 & 64.1 \\
\hline & (dBZ) & 89.5 & 91.7 & 89.4 & 82.3 & 89.0 & 92.1 & 87.2 & 84.2 & 87.5 & 90.4 & 86.6 & 84.6 \\
\hline \multirow[t]{2}{*}{ Soundwalk 05} & $(\mathrm{dBA})$ & - & - & - & - & 62.3 & 64.7 & 55.9 & 49.4 & - & - & - & - \\
\hline & (dBZ) & - & - & - & - & 82.3 & 84.0 & 81.2 & 78.9 & - & - & - & - \\
\hline Fixed-point & $(\mathrm{dBA})$ & - & - & - & - & 54.6 & 58.2 & 51.7 & 47.6 & - & - & - & \\
\hline Residential compound & (dBZ) & - & - & - & - & 69.9 & 74.6 & 63.9 & 59.3 & - & - & - & \\
\hline
\end{tabular}

When A- and Z-weighted SPLs are compared, it can be clearly observed that the Z-weighted values of $L_{e q}$ and $L_{n}$ are significantly higher than the A-weighted values in all of the measurements. Thus, the conclusion can be drawn that middle- and low-frequency sounds contribute remarkably to the sound environment.

The LSR (least significant ranges) method for multiple comparison was employed by Duncan's multiple range test to identify whether there were significant variations between each measurement. This method was developed by Duncan (1955) and used to test for significant differences between treatments (Panneerselvam, 2004). Letter notation is applied to present the results. That is, capital letters are used when the significance level $\alpha=0.01$ (very significant variation), and the lower case is used when 
Lingjiang Huang \& Jian Kang: Sound Environment and Soundscape Preservation

doi:10.1068/b130073p

$\alpha=0.05$ (significant variation). When the different control groups are marked with the same lowe rcase or capital letters, it indicates that no significant or very significant variance can be found between; otherwise, different letters indicate significant difference. If any control group is marked with more than one letter, it means the control group has no significant variation with any of the groups that contain the same letter (Gomez, 1984).

When the measurement periods are considered as control groups, it can be observed in Table 6 that during Soundwalks 01, 02 and 03, all the $p$-values were far lower than significance level $\alpha=0.05$ and the $F$ values were far higher than the $F$ crit values, which indicates there were significant SPL variations during all of the periods. However, Soundwalk 04 exhibited different scenarios because the $p$-values were higher than significance level $\alpha=0.05$ and the F value was much lower than the F crit value, which indicates there were no significant SPL variations in any of the periods.

Further comparisons of significance of variation show that Soundwalk 01 exhibited a similar sound environment during the morning and noon periods, and Soundwalks 02 and 03 displayed similar sound environments during the morning and evening periods, whereas the noon periods were significantly higher.

Table 6. Multiple comparisons for each of the four soundwalk measurements

\begin{tabular}{|c|c|c|c|c|c|c|}
\hline \multirow[t]{2}{*}{ NO. } & \multirow[t]{2}{*}{$\mathrm{F}$} & \multirow[t]{2}{*}{ P-value } & \multirow[t]{2}{*}{ F crit } & \multirow[t]{2}{*}{ Group } & \multicolumn{2}{|c|}{ Significance of variation } \\
\hline & & & & & 0.05 & 0.01 \\
\hline \multirow[t]{3}{*}{ Soundwalk 01} & 17.60 & $8.55 \mathrm{E}-08$ & 3.04 & Morning & $\mathrm{a}$ & A \\
\hline & & & & Noon & a & A \\
\hline & & & & Evening & $\mathrm{b}$ & $\mathrm{B}$ \\
\hline \multirow[t]{3}{*}{ Soundwalk 02} & 16.72 & $3.73 \mathrm{E}-07$ & 3.07 & Morning & $\mathrm{b}$ & B \\
\hline & & & & Noon & $\mathrm{a}$ & A \\
\hline & & & & Evening & $\mathrm{b}$ & B \\
\hline \multirow[t]{3}{*}{ Soundwalk 03} & 37.90 & 5.32E-14 & 3.06 & Morning & $\mathrm{b}$ & B \\
\hline & & & & Noon & $\mathrm{a}$ & A \\
\hline & & & & Evening & $\mathrm{b}$ & B \\
\hline \multirow[t]{3}{*}{ Soundwalk 04} & 0.09 & 9.09E-01 & 3.04 & Morning & $\mathrm{a}$ & A \\
\hline & & & & Noon & $\mathrm{a}$ & A \\
\hline & & & & Evening & $\mathrm{a}$ & A \\
\hline
\end{tabular}

Different letters indicate significant differences at $\mathrm{p}<0.05$ (in lowercase) and $\mathrm{p}<0.01$ (in capital) using Duncan's Multiple Range Test. 


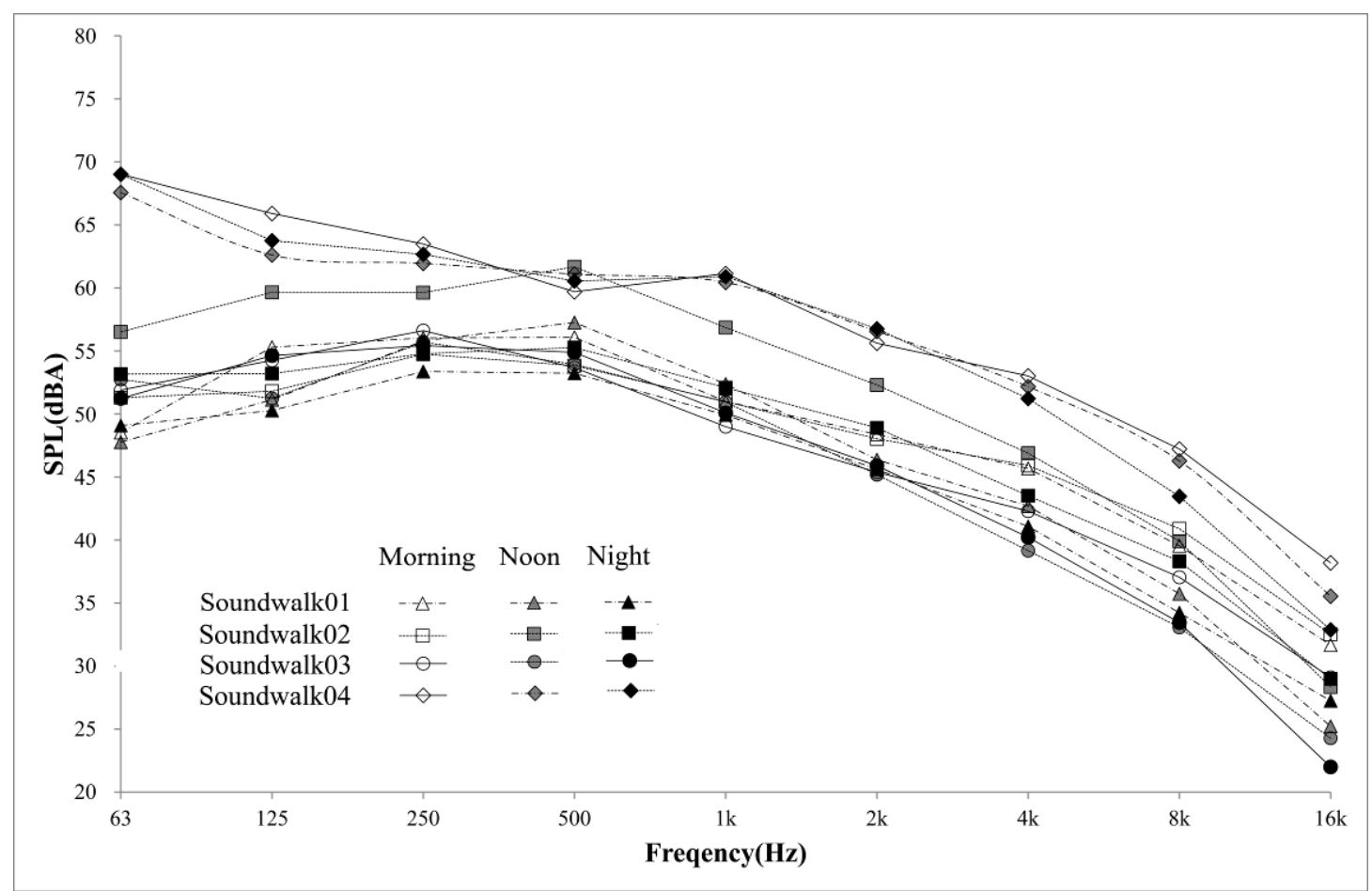

Fig. 8. Measured spectra of the four soundwalks, based on the average over the duration of each soundwalk

\subsection{Changes of sound environment with frequency}

Figure 8 shows the spectrum of the four soundwalks, based on the average over the duration of each. It can be observed that the spectrum of the pedestrian areas has highly similar trends, where the highest SPL is between $250 \mathrm{~Hz}$ and $500 \mathrm{~Hz}$ and approximately 50-60 dB, whereas a substantial decrease can be observed at higher frequencies. For the spectrum of Soundwalk 04 with motor-vehicle traffic, the SPL is much higher than that of the pedestrian soundwalks at all frequencies, and sounds of $63 \mathrm{~Hz}$ and $125 \mathrm{~Hz}$ are found to be the highest during all of the periods; the SPL decreases as the frequency increases.

Table 7 displays the results of the multiple comparisons within each frequency when the measurement periods were considered as control groups. Similarity can be observed in the soundwalks conducted in pedestrian areas, namely, Soundwalks 01 to 03, where sound showed significant variations in the spectrum, but sounds between $250 \mathrm{~Hz}$ and $500 \mathrm{~Hz}$ had the highest values and showed no significant variations during any of the periods, likely owing to the dominant contribution from human Environment and Planning B: Planning and Design 2015, Volume 42, Pages 652-674 
Lingjiang Huang \& Jian Kang: Sound Environment and Soundscape Preservation

doi:10.1068/b130073p

voices and the clip-clop sound of footsteps. For Soundwalk 04, the lowest frequency had the highest values, $63 \mathrm{~Hz}$ and $125 \mathrm{~Hz}$, and between $250 \mathrm{~Hz}$ and $1 \mathrm{kHz}$, there were no significant variations during any of the periods.

Table 7. Multiple comparisons of the spectra of the four soundwalks during each measurement $(\alpha=0.01)$ 错误!未找到引用源。

\begin{tabular}{|c|c|c|c|c|c|c|c|c|c|c|c|c|}
\hline \multirow{2}{*}{ 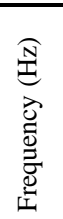 } & \multicolumn{3}{|c|}{ Soundwalk 01} & \multicolumn{3}{|c|}{ Soundwalk 02} & \multicolumn{3}{|c|}{ Soundwalk 03} & \multicolumn{3}{|c|}{ Soundwalk 04} \\
\hline & $\begin{array}{l}\stackrel{\infty}{\Xi} \\
\stackrel{\Xi}{\Xi} \\
\sum\end{array}$ & $\begin{array}{l}\tilde{8} \\
\text { Z }\end{array}$ & 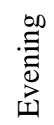 & $\begin{array}{l}\stackrel{\infty}{:} \\
\text { 泀 } \\
\sum_{\Sigma}\end{array}$ & $\begin{array}{l}\tilde{8} \\
\text { Z }\end{array}$ & 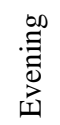 & 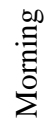 & $\begin{array}{l}\text { ठ̊ } \\
\text { Z }\end{array}$ & 唄 & $\begin{array}{l}\stackrel{\infty}{0} \\
\stackrel{\Xi}{\mid} \\
\stackrel{0}{\Sigma}\end{array}$ & $\begin{array}{l}\tilde{8} \\
\text { Z }\end{array}$ & 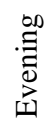 \\
\hline 63 & B & $\mathrm{C}$ & B & B & B & $\mathrm{AB}$ & $\mathrm{C}$ & B & B & A & A & A \\
\hline 125 & A & B & B & B & $\mathrm{AB}$ & $\mathrm{AB}$ & B & B & A & B & B & B \\
\hline 250 & A & A & A & A & $\mathrm{AB}$ & $\mathrm{AB}$ & A & A & A & $\mathrm{BC}$ & B & $B C$ \\
\hline 500 & A & A & A & $\mathrm{AB}$ & A & A & B & $\mathrm{AB}$ & A & $\mathrm{C}$ & B & $\mathrm{C}$ \\
\hline $1 \mathrm{k}$ & B & B & B & B & B & B & $\mathrm{D}$ & B & B & $\mathrm{C}$ & B & $\mathrm{C}$ \\
\hline $2 \mathrm{k}$ & $\mathrm{E}$ & $\mathrm{C}$ & $\mathrm{C}$ & $\mathrm{C}$ & $\mathrm{C}$ & $\mathrm{C}$ & $\mathrm{E}$ & $\mathrm{C}$ & $\mathrm{C}$ & D & $\mathrm{C}$ & $\mathrm{D}$ \\
\hline $4 \mathrm{k}$ & $\mathrm{D}$ & $\mathrm{D}$ & $\mathrm{D}$ & $\mathrm{C}$ & $\mathrm{D}$ & D & $\mathrm{F}$ & $\mathrm{D}$ & $\mathrm{D}$ & D & $\mathrm{D}$ & $\mathrm{E}$ \\
\hline $8 \mathrm{k}$ & $\mathrm{E}$ & $\mathrm{E}$ & E & $\mathrm{D}$ & E & E & G & $\mathrm{E}$ & $\mathrm{E}$ & $\mathrm{E}$ & E & $\mathrm{F}$ \\
\hline $16 \mathrm{k}$ & $\mathrm{F}$ & $\mathrm{F}$ & $\mathrm{F}$ & E & $\mathrm{F}$ & $\mathrm{F}$ & $\mathrm{H}$ & $\mathrm{F}$ & $\mathrm{F}$ & $\mathrm{F}$ & $\mathrm{F}$ & G \\
\hline
\end{tabular}

Different letters indicate significant differences at $\mathrm{p}<0.01$ (in capital) using Duncan's Multiple Range Test. A marking with more than one letter indicates that the control group has no significant variation with any of the groups that contain the same letter.

\section{Comparisons with Other Historic Centres and Preservation Strategies}

\subsection{Comparisons of Lhasa's historic centre with those of other cities}

To have a comprehensive understanding of the sound environment of Lhasa's historic centre, the results were compared with those of a number of historic centres and squares in Italy, Turkey and Spain based on relevant studies by other researchers (Brambilla et al, 2007; Barrigón et al, 2013; Escobar et al, 2012; Marletta et al, 2007).

In terms of sound sources, the sounds of music, human voices, steps and vehicles could all be perceived in Lhasa, Istanbul, Naples and Cáceres, whereas religious sounds were absent in Istanbul and Naples and only church bells could be heard in Cáceres. However, in Lhasa, various religious sounds could be clearly identified during certain soundwalks. Regarding soundmarks, in two Italian historic squares, 
Bologna and Catania, the sounds of fountains, which are passive sounds related to landscape elements, were identified as soundmarks rather than other sounds (Zhang and Kang, 2007). Conversely, in Lhasa's historic centre, most of the soundmarks are anthropic sounds, which are active sounds from activities in the spaces.

In terms of SPL ( $\left.\mathrm{L}_{\mathrm{eqA}}, \mathrm{L}_{90}\right)$ during working hours, the SPL of Lhasa's commercial areas (soundwalk01) (69.2 dBA, 60.1 dBA) was found to be lower than those of Istanbul (74.3 dBA, $67.8 \mathrm{dBA})$ and Naples (72.7 dBA, $65.7 \mathrm{dBA})$. The SPL of Lhasa's historic market (soundwalk02) (72.9 dBA, 65.1 dBA) was slightly higher than that in Istanbul (72.6 dBA, $61.1 \mathrm{dBA}$ ) but remarkably lower than that in Naples (76.0 dBA, 67.5 dBA). The SPL of Lhasa's religious area (Soundwalk01) (69.2 dBA, 60.1 dBA) was much higher than those for both Istanbul (59.7 dBA, $48.5 \mathrm{dBA}$ ) and Naples (54.7 dBA, $48.0 \mathrm{dBA}$ ). One possible reason is that the religious area in Lhasa's historic centre is mixed with a commercial area. When compared with the centre of Cáceres in Spain, the SPL of all areas of Lhasa's historic centre including the residential compound was much higher.

The spectrum of pedestrian areas of Lhasa's historic centre showed similar patterns to those of commercial areas in both Istanbul and Naples, but the spectra of soundmarks differed significantly. Traffic noise was found to influence all of the sound environments in the historic centres and squares including Lhasa, but it was the anthropic sounds that contribute most to the sound environment in the core area of Lhasa's historic centre, whereas traffic noise mainly influences the outer area.

Overall, all of these historic environments share some common characteristics such as certain soundmarks and threats of traffic noise. However, notable differences can be found between Lhasa and other historic sound environments. Firstly, more soundmarks can be perceived in Lhasa's historic centre, most of which are active sounds. This result could lead to differences in preservation strategies, namely, the preservation of traditional activities in Lhasa. Secondly, the sound level of the religious area in Lhasa's historic centre is much higher because of the mixed functions. Thirdly, the effect of traffic noise is much less in the core area of Lhasa's historic centre than it is in other historic centres or squares. 


\subsection{Preservation strategies}

In general, soundscape preservation should consider the relationships between sound, space and people's perceptions (Kang et al, 2004; Kang, 2007). A key principle is to preserve the soundmarks from the traditional social activities and the spaces where the soundmarks are generated and transmitted. It is important to identify the historic soundmarks that are considered 'wanted sounds' as well as sound intruders, which are considered 'unwanted sound'. The overall sound level of the historic environment also needs to be evaluated, and the areas where SPLs are higher than a certain value should be zoned. The background sound levels should be reduced for the audibility of preferred sound sources. More detailed analysis should also be carried out in terms of spectrum.

In the case of Lhasa, based on the measured SPL values of the sound environment, a series of sound maps could be generated using acoustic simulation software to display the spatial and temporal variation of the sound environment and soundmarks, so that spaces where sound environment is poor and soundmarks might be affected can be identified. In the meantime, based on the soundwalk measurements, certain sound sources with peak sound levels can be identified, and corresponding preservation strategies can be implemented. Figures 9a-c shows the sound environment of Lhasa's historic city centre in various periods using CadnaA (DataKustik $\mathrm{GmbH}, 2005$ ) software. It can be observed that the traffic noise on East Peking Street has considerable impact on the north part of the historic centre. However, the historic urban fabric, particularly the labyrinthine alleys, are effective sound barriers to avoid soundscape conflicts by separating areas with traffic noise and anthropic sounds, and separating quiet residential compounds from noisy commercial streets. Thus, preservation of the historic urban fabric should be considered an important strategy for soundscape preservation. Areas of high SPL, e.g., $70 \mathrm{dBA}$, can be clearly identified, which are the Jokhang temple square during the noon period (Figure 9b), the 'Bakor' street and the local commercial market street during both the morning and noon periods (Figure 9a, 9b), and East Peking Street all day (Figure 9a, 9b, 9c). These spaces might be acoustically uncomfortable areas that affect the perception of positive sound sources. Thus, noise reduction strategies should be proposed in these spaces, such as speed limits and the restriction of certain commercial activities. 
doi:10.1068/b130073p

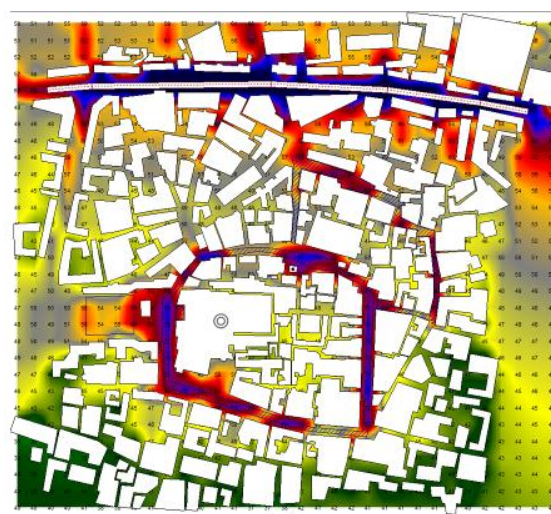

(a)

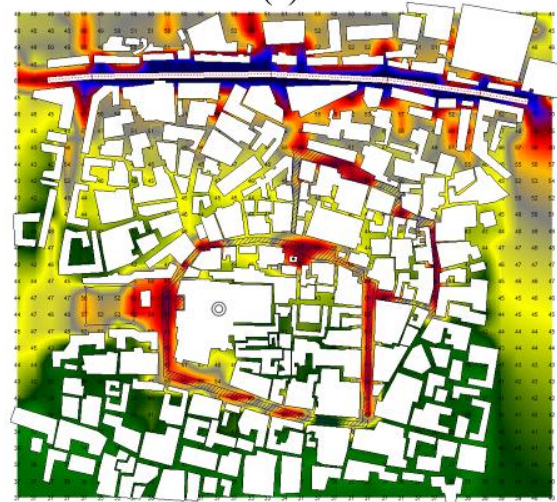

(c)

() Jokhang Temple

- Mani Lhakhang temple

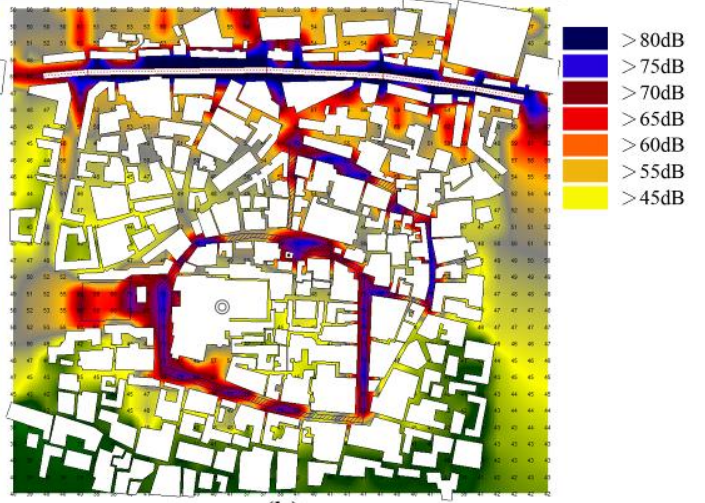

(b)

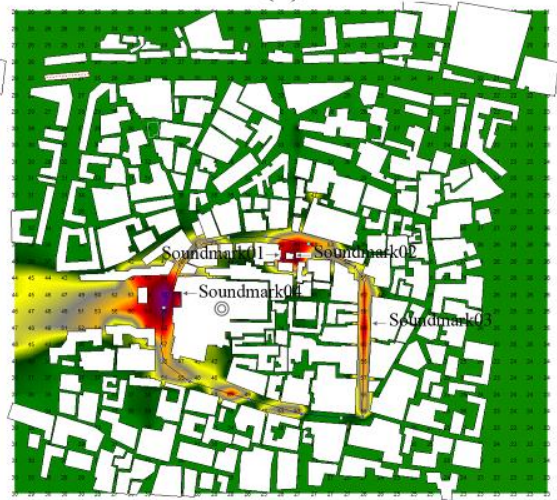

(d)

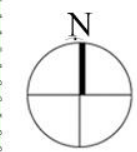

$\underline{0 \quad 100 \quad 200}$

Fig. 9. Soundmaps of the historic city centre: (a) Sound level distribution during the morning period; (b) Sound level distribution during the noon period; (c) Sound level distribution during the evening period; (d) Sound distribution of soundmarks

The spatial patterns of the soundmarks' influence are shown in Figure 9d, again based on simulation using CadnaA, where the soundmarks are assumed to be the only sound sources in the environment and are defined as point sound source, line source or area source where appropriate. It can be observed that the spaces in front of the Jokhang and Mani Lhakhang temples are important places where soundmark01, soundmark02 and soundmark03 have considerable influence, so that preservation is needed. As a moving sound source, soundmark04 is found to be more audible in the east part of the 'Bakor' street, and a special route along the 'Bakor'street is suggested for pilgrims only. Music from the shops' loudspeakers, which generated sound peaks over $70 \mathrm{dBA}$ on both Soundwalks 01 and 02 during the noon and evening periods, should also be reduced. 
Lingjiang Huang \& Jian Kang: Sound Environment and Soundscape Preservation

doi:10.1068/b130073p

\section{Conclusions}

In this study, the characteristics of the sound environment of Lhasa's historic city centre during the high tourism season were analysed based on field investigation and measurements conducted during soundwalks and on fixed-point measurement. Sixteen sound sources were categorised as five sound types: ambient, informative, religious, natural sound and traffic noise. Some of the sounds were found to exist in their traditional form and should be regarded as soundmarks with 'place identities', which require preservation. In terms of physical properties, the soundmarks differed significantly from each other. However, all soundmarks had higher SPLs than those of soundwalks.

The sounds were found to have highly distinct spatial and temporal distributions. Human voices were found to be the only sounds that occurred on all of the soundwalk routes and during all of the periods. The sounds of the mantra being recited and the ringing of wind bells could be heard clearly. Religious sounds occurred frequently and shaped most of the sound peaks. The results also indicate that in the pedestrian areas, there were significant variations between the different periods for each soundwalk, which implies a variety of sound sources and activities during the different periods. The Z-weighted SPL was found to be remarkably higher than the A-weighted value in all of the measurements, which indicates that middle- and low-frequency sounds played an important role in the sound environment. The spectrums along the different soundwalk routes in the pedestrian areas were found to be rather consistent, with a peak between $250 \mathrm{~Hz}$ and $500 \mathrm{~Hz}$.

Compared with other historic environments, more active soundmarks can be perceived in Lhasa's historic centre. There is remarkably higher SPL in the religious area of Lhasa's city centre, possibly owing to the mixed functions. Traffic noise has considerable impacts on the outer part of the historic centre, but the impact is much less on the core area owing to the labyrinthine urban fabric.

While the above results reveal that the sound environment and soundmarks in Lhasa's historic city centre have unique characteristics and cultural contexts, based on the analyses of possible soundscape preservation strategies for Lhasa, several general 
Lingjiang Huang \& Jian Kang: Sound Environment and Soundscape Preservation doi:10.1068/b130073p

preservation strategies have been discussed.

\section{References}

Axelsson, Ö. (Ed.), 2011, Designing Soundscape for Sustainable Urban Development (Stockholm, Sweden: City of Stockholm) pp15

Barrigón Morillas J M, Gómez Escobar V, Rey Gozalo G, 2013,"Noise source analyses in the acoustical environment of the medieval centre of Cáceres (Spain)" Applied Acoustics 74 526-534

Basangjiba, 2009, "On the Changes of Lhasa City before 1950s" Journal of Tibet University 24(3) 40-44 (in Chinese)

Brambilla G, De Gregorio L, Maffei L, Can, Z Y, Ozcevik A, 2007, “Comparison of the soundscape in the historical centres of Istanbul and Naples" in Proceedings of Inter-noise07 Istanbul, Turkey, International Institute of Noise Control Engineering

Brambilla, G, Maffei, L, 2010, "Perspective of the soundscape approach as a tool for urban space design " Noise Control Engineering Journal 58 (5) 532-539

Brown A L, Kang J, Gjestland T, 2011, "Towards standardising methods in soundscape preference assessment". Applied Acoustics 72 387-392.

DataKustik GmbH, 2005, Cadna/A for Windows - User Manual (Munich)

Deng Z, Wu W, Shi D, 2009, "Two case studies on the soundscape in historical area and its subjective assessment from the local people", in Proceedings of Inter-noise09 Ottawa, Canada, International Institute of Noise Control Engineering

Duncan, D B, 1955, “Multiple range and multiple F tests”. Biometrics. 11 1-42

Erendil A T, Ulusoy Z, 2002, "Reinvention of tradition as an urban image: the case of Ankara Citadel” Environment and Planning B: Planning and Design 29 655-672

Garrioch D, 2003, "Sounds of the city: the soundscape of early modern European towns" Urban History 30(1) 5-25

Gómez Escobar V, Barrigón Morillas J M, Rey Gozalo G, Vaquero J M, Méndez Sierra J A, Vílchez Gómez R, Carmona del Río F J, 2012,"Acoustical environment of the medieval centre of Cáceres (Spain)" Applied Acoustics 73 673-685

Gomez K A, Gomez A A, 1984 Statistical Procedures for Agricultural Research (Vol. 680) (Wiley, New York) pp 213-214

Huang L, Liu C, 2010,"The image-meaning relationship between Tibetan traditional architecture and religious culture" Huazhong Architecture 5 134-137(in Chinese)

Kang J, 2007 Urban Sound Environment (Taylor \& Francis, London) pp 27

Environment and Planning B: Planning and Design 2015, Volume 42, Pages 652-674 
Lingjiang Huang \& Jian Kang: Sound Environment and Soundscape Preservation

doi:10.1068/b130073p

Kang J, Yang W, Zhang M, 2004, "Sound environment and acoustic comfort in urban spaces", in Designing Open Spaces in the Urban Environment: A Bioclimatic Approach Ed. M Nikolopoulou (European Commission and the Centre for Renewable Energy Sources, Brussels) pp 32-36

Knud L, Amund S, 2005 The Lhasa Atlas: Traditional Tibetan Architecture and Townscape (Serindia Publications, Chicago) p22

Marletta L, Evola G, Sicurella F, 2007,“Acoustic characterisation of historical squares: two examples in Italy", in Proceedings of Inter-noise07 Istanbul, Turkey, International Institute of Noise Control Engineering

Nijkamp P, 1987, "Culture and region: a multidimensional evaluation of monuments" Environment and Planning B: Planning and Design 15(1) 5-14

Panneerselvam, R. 2004. Research methodology. (PHI Learning Pvt. Ltd., New Dehli) pp98

Smith, B.R., 2000, The Acoustic World of Early Modern England: Attending to the $O$-factor (University of Chicago Press: Chicago)

Yang W, Kang J, 2003, “A cross-cultural study of the soundscape in urban open public spaces" in Proceedings of the 10th International Congress on Sound and Vibration Stockholm, Sweden, pp 2703-2710

Yang W, Kang J, 2005a,"Acoustic comfort evaluation in urban open public space" Applied Acoustics 66 211-229

Yang W, Kang J, 2005b, "Soundscape and sound preferences in urban squares" Journal of Urban Design 10 69-88

Yin H, 2009, "Summary of the formation and development of Lhasa city" Journal of Tibet University 24(2) 54-62(in Chinese)

Zhang M, Chen C, 2007,"Weltanschauung of Tibetan traditional settlement and Tibetan Buddhism” Religious Study (2) 201-206 (in Chinese)

Zhang M, Kang J, 2007, "Towards the evaluation, description, and creation of soundscapes in urban open spaces" Environment and Planning B: Planning and Design 34 68-86 